\title{
BMJ
}

\section{Impact of rapid screening tests on acquisition of meticillin resistant Staphylococcus aureus: cluster randomised crossover trial}

\author{
Dakshika Jeyaratnam, research fellow, ${ }^{1,2}$ Christopher J M Whitty, professor , ${ }^{3}$ Katie Phillips, medical \\ laboratory assistant, ${ }^{1}$ Dongmei Liu, medical statistician, ${ }^{3}$ Christina Orezzi, information analyst, ${ }^{1}$ \\ Uchechukwu Ajoku, research assistant, ${ }^{1}$ Gary L French, professor of microbiology ${ }^{1,2}$
}

'Department of Infection, Guys and St Thomas' NHS Foundation Trust, London

${ }^{2}$ Department of Infectious Diseases, King's College London School of Medicine

${ }^{3}$ Department of Infectious and Tropical Diseases, London School of Hygiene and Tropical Medicine, London

Correspondence to: D Jeyaratnam, Health Protection Agency Regional Laboratory (Microbiology), King's College Hospital NHS Foundation Trust, London SE5 9RS dakshika.jeyaratnam@kcl.ac.uk

doi:10.1136/bmj.39525.579063.BE

\section{ABSTRACT}

Objective To determine whether introducing a rapid test for meticillin resistant Staphylococcus aureus (MRSA) screening leads to a reduction in MRSA acquisition on hospital general wards.

Design Cluster randomised crossover trial. Setting Medical, surgical, elderly care, and oncology wards of a London teaching hospital on two sites.

Main outcome measure MRSA acquisition rate (proportion of patients negative for MRSA who became MRSA positive).

Participants All patients admitted to the study wards who were MRSA negative on admission and screened for MRSA on discharge.

Intervention Rapid polymerase chain reaction based screening test for MRSA compared with conventional culture.

Results Of 9608 patients admitted to study wards, 8374 met entry criteria and 6888 had full data (82.3\%); 3335 in the control arm and 3553 in the rapid test arm. The overal MRSA carriage rate on admission was $6.7 \%$. Rapid tests led to a reduction in median reporting time from admission, from 46 to 22 hours ( $\mathrm{P}<0.001)$. Rapid testing also reduced the number of inappropriate pre-emptive isolation days between the control and intervention arms (399 v 277, P<0.001). This was not seen in other measurements of resource use. MRSA was acquired by 108 (3.2\%) patients in the control arm and 99 (2.8\%) in the intervention arm. When predefined confounding factors were taken into account the adjusted odds ratio was 0.91 ( $95 \%$ confidence interval 0.61 to 1.234 ). Rates of MRSA transmission, wound infection, and bacteraemia were not statistically different between the two arms.

Conclusion A rapid test for MRSA led to the quick receipt of results and had an impact on bed usage. No evidence was found of a significant reduction in MRSA acquisition and on these data it is unlikely that the increased costs of rapid tests can be justified compared with alternative control measures against MRSA.

Trial registration Clinical controlled trials ISRCTN75590122.

\section{INTRODUCTION}

Infections with meticillin resistant Staphylococcus aureus (MRSA) are endemic in UK hospitals. In England MRSA accounts for about $36 \%$ of hospital bacteraemias caused by $S$ aureus and $64 \%$ of Saureus surgical site infections. ${ }^{1}$ MRSA infections are associated with higher morbidity and mortality rates, longer hospital stays, and increased costs than those caused by meticillin susceptible Saureus(MSSA). ${ }^{23}$ The reduction of healthcare associated infections, including those caused by MRSA, is a government priority. ${ }^{4}$

In the UK most MRSA is associated with hospitals or other healthcare facilities, and patients who are colonised at discharge often reintroduce MRSA on readmission or transfer between institutions. ${ }^{5}$ It is widely recommended that patients at risk of MRSA carriage should be screened on or before hospital admission to guide the implementation of enhanced control measures. ${ }^{6-11}$ Universal screening has recently been suggested for UK national policy. ${ }^{12}$

Conventional culture methods for MRSA screening take 1-5 days (usually 2-3 days) to produce a positive result. Polymerase chain reaction based systems are now available that detect MRSA usually within one day. It is hypothesised that rapid detection of MRSA carriers will lead to faster implementation of control procedures, reducing the transmission of MRSA. ${ }^{612}$ The strong political pressure to reduce MRSA rates means that rapid screening, which is significantly more costly_about $£ 10(€ 13 ; \$ 21)$ for rapid tests compared with less than $£ 2$ for conventional tests (not accounting for staff costs) - is under consideration. The increased cost of rapid tests might be offset by savings as a result of reduced cross infection, fewer complications, and better utilisation of beds.

Five reports exist on the impact of rapid polymerase chain reaction tests for MRSA, four using historical controls rather than a trial design; two were restricted to intensive care settings. A UK cohort study showed a significant reduction in rates of MRSA transmission when rapid testing was used to screen patients admitted to intensive care. ${ }^{13}$ Another study investigated the use 
of rapid screening for MRSA on two intensive care units, medical and surgical: a reduction in intensive care unit acquired MRSA infections occurred in the medical setting only when pre-emptive isolation of all patients was added to rapid testing, but no effect was found on the surgical intensive care unit, which already pre-emptively isolated patients at high risk of MRSA. ${ }^{14}$ The third study used a rapid test in a tertiary referral hospital. ${ }^{15}$ Although specimens were cultured overnight, before polymerase chain reaction testing, contact precautions were initiated significantly earlier when polymerase chain reaction testing was used ; this group found an insignificant reduction of MRSA colonisation or infection and an increase in the cost of MRSA control. ${ }^{15}$ In another uncontrolled study, rapid screening for MRSA in patients admitted for elective or emergency surgery was associated with a significant reduction in both MRSA and MSSA bacteraemia. MRSA but not MSSA wound infections also decreased. ${ }^{16}$ A prospective cohort study did not find a reduction in nosocomial MRSA infection rates in surgical patients when universal, rapid MRSA screening was added to standard infection control measures. ${ }^{17}$

Current evidence is insufficient to extend rapid testing to universal screening given the substantial implications on resources. We carried out a randomised trial to test whether universal, rapid screening for MRSA leads to a reduction in MRSA acquisition on general wards.

\section{METHODS}

The study was carried out at a London teaching hospital (1200 beds) on two sites over 14 months. We used a randomised, unblinded, crossover trial design, with 10 wards randomised to receive either rapid screening for MRSA or conventional culture screening, to guide clinical treatment. After the first intervention period there was a washout period, after which the wards swapped screening methods. We studied two care of the elderly wards, two oncology wards, and six surgical wards. These wards had endemic MRSA and were representative of hospital settings where MRSA occurs. Randomisation was undertaken by random number tables on a different site (London School of Hygiene and Tropical Medicine). Patients were screened at the nares, axillae, and groin; skin breaks; and clinically indicated sites. We pooled the swabs taken from the nares, axillae, and groin. The intervention was a polymerase chain reaction test $(\mathrm{BD}$ GeneOhm MRSA Assay; Becton Dickinson, NJ, USA) used to screen for MRSA on admission. The test produces a result for MRSA in less than two hours of laboratory time. The control was conventional culture, which produces a positive result for MRSA after at least 72 hours and a negative result after 24 hours.

All patients admitted to the wards were eligible for inclusion. After the patients had given verbal consent, ward staff screened them for MRSA on admission and at discharge. We considered specimens taken within 48 hours of admission and discharge (after ward transfer) as valid. We excluded from the analysis those patients who were MRSA positive on admission-defined as any specimen culture positive for MRSA that was taken up to five days before hospital admission or 48 hours after admission to a study ward or patients transferred from hospitals who were positive for MRSA. We excluded patients who did not consent to swabbing or who had not been swabbed at the nares, axillae, and groin within 48 hours of admission.

Except for rapid testing, MRSA control policies were in accordance with national guidelines. ${ }^{818}$ We applied standard precautions to all patients; those positive for MRSA were isolated and contact precautions applied, including hand hygiene, the use of gloves and disposable plastic gowns, and safe disposal of all potentially contaminated material. Isolation was in a side room when possible or in a designated ward area, usually in bays with other MRSA positive patients (cohorting). ${ }^{8}$ MRSA positive patients started decolonisation treatment with chlorhexidine based cleansing solution and powder and, depending on sensitivity, mupirocin nasal ointment. Colonised wounds were treated with povidone iodine or silver sulphadiazine preparations when possible. MRSA positive patients were rescreened weekly and were considered MRSA positive until results were negative on three, consecutive, weekly MRSA screens. Some surgical patients were screened for MRSA in preadmission clinics and, if they were MRSA positive, their admissions were postponed pending decolonisation. Patients considered high risk for MRSA carriage (previous colonisation or infection with MRSA; living in a nursing or residential home; an inpatient in the previous year; or a direct transfer from another hospital, abroad, or a high risk area within the hospital) were pre-emptively isolated or cohort nursed in a bay from the time of admission, pending screening results; this was stopped if they were MRSA negative on admission screening.

\section{Outcome measures}

The primary outcome was the rate of MRSA acquisition-patient became MRSA culture positive on screens or clinical specimens taken more than 48 hours after admission and 48 hours or less after discharge. Major secondary outcomes were rate of MRSA acquisition per 1000 patient days at risk; MRSA transmission rate-ratio of patients who were MRSA positive on admission to the number of MRSA acquisitions; and the number of patients with MRSA wound infection and the number with bacteraemia acquired during the study ward stay - that is, culture positive wound specimens and culture positive blood cultures, respectively. We considered one infection per patient per admission. Resource outcomes were the number of days that patients were pre-emptively nursed with MRSA precautions but were not MRSA positive on admission ("inappropriately isolated or cohorted"), or nursed without precautions and were MRSA positive on admission ("inappropriately open"). We determined the sensitivity and specificity of polymerase chain reaction testing on the admission 
specimen, which included swabs of the nares, axillae, and groin, compared with conventional culture.

\section{Intervention and control arms}

In the control arm samples were taken on admission for culture only. In the rapid test arm two samples were taken on admission, one for rapid testing (to guide clinical management) and the other for conventional culture (to compare like with like, although results were subsequently reported to the wards). Swabs taken on discharge were processed only by culture and we compared the results with admission culture results. The arms were otherwise treated identically; the difference between arms was that rapid test results from admission were available in the intervention arm.

We cultured the swabs in MRSA selective broth ${ }^{19}$ and, after May 2006, combined this with MRSA Chromagar (Oxoid, Basingstoke, UK). Susceptibility to meticillin was determined by $\operatorname{disc}^{20}$ or automated (VITEK2; Biomerieux, Basingstoke, UK) testing. Culture and polymerase chain reaction tests were processed until $7 \mathrm{pm}$ on weekdays and once daily on weekends. Before this study we validated the polymerase chain reaction test for use on pooled and nonnasal specimens. ${ }^{21}$ MRSA positive results were communicated directly to the wards as soon as possible. We define the turnaround time as the time between admission to the study ward and the result of the admission sample that determined MRSA status.

\section{Data collection}

We collected data on potential confounding factors for all patients. We noted personal details, the American Society of Anesthesiology score for physical status, ${ }^{22}$ temporary transfers to other hospital areas, and infection control measures. We collected potential ward confounding factors monthly; these were compliance with hand hygiene policy by unobtrusive direct observation, bed occupancy, antibiotic use from

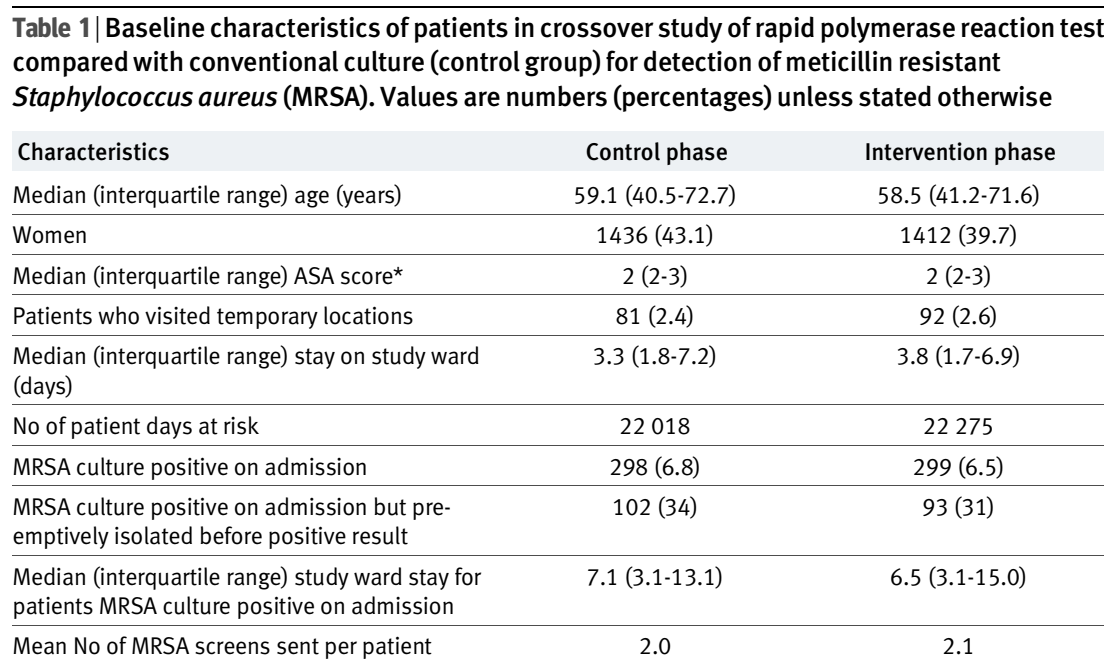

Data for all patients included in analysis of primary and major secondary outcomes (except data for patients MRSA culture positive on admission).

*American Society of Anesthesiology score for physical status: from 1 (completely healthy) to 5 (moribund, not expected to live 24 hours). pharmacy records, staffing numbers, temporary staff levels, the number of beds and side rooms open, the number of MRSA culture positive patients with and without isolation precautions, the percentage of patients MRSA positive on admission that were isolated at admission, and MRSA importation pressure - that is, the proportion of patients who were MRSA positive on admission.

\section{Statistical analysis}

We determined that, with an estimated MRSA acquisition rate of $2 \%$ and a halving of transmission to $1 \%$ we required 3330 patients in each arm, accounting for the cluster design. This study size would detect a reduction from $3.0 \%$ to $1.9 \%$ and from $4.0 \%$ to $2.7 \%$ at a significance level of $5 \%$ and $80 \%$ power. We considered reductions smaller than this unlikely to trigger a change in practice given the implications on resources. Data were entered into Microsoft Access and analysed using Stata version 9.0. We finalised the analytical plan before data analysis. For primary and secondary outcomes we designated patients who were not correctly swabbed at discharge as "lost to follow-up." We calculated unadjusted odds ratios and then adjusted them in a generalised estimating equation regression model, with logit link for acquisition rate taking into account the cluster randomised design, with the predefined potential confounding factors of age, sex, American Society of Anesthesiology score, ward type, and length of stay on the study ward. We adjusted standard errors for correlation within wards. Odds ratios of regression coefficients are reported. To check for significant differences in sampling across wards, we constructed a summary score, taking potential factors likely to affect within ward and between ward transmission pressure and tested the homogeneity of the distribution score across wards. We carried out a further restricted primary outcome analysis, where we excluded all patients with any MRSA culture positive specimen within three months before admission, and those with MRSA positive discharge screens taken within 48 hours of a negative admission swab. In the resource analysis we included patients who were MRSA positive on admission and those lost to follow-up.

\section{RESULTS}

The study ran from January 2006 to March 2007 and comprised a three month baseline period, five month intervention period, one month washout period, and five month second intervention period. During the intervention periods 9608 patients were admitted to the study wards; $637(6.6 \%)$ did not meet the inclusion criteria. The figure shows the flow of participants through the study. Overall, 597 (6.7\%) swabbed patients were culture positive for MRSA on admission (298 in the control arm, 299 in the rapid test arm). Of 8374 patients who met the study entry criteria, 1486 $(17.8 \%)$ were lost to follow-up (18.6\% in the control arm, $16.9 \%$ in the rapid test arm). In both arms $99 \%$ of the patients lost to follow-up were not swabbed on 


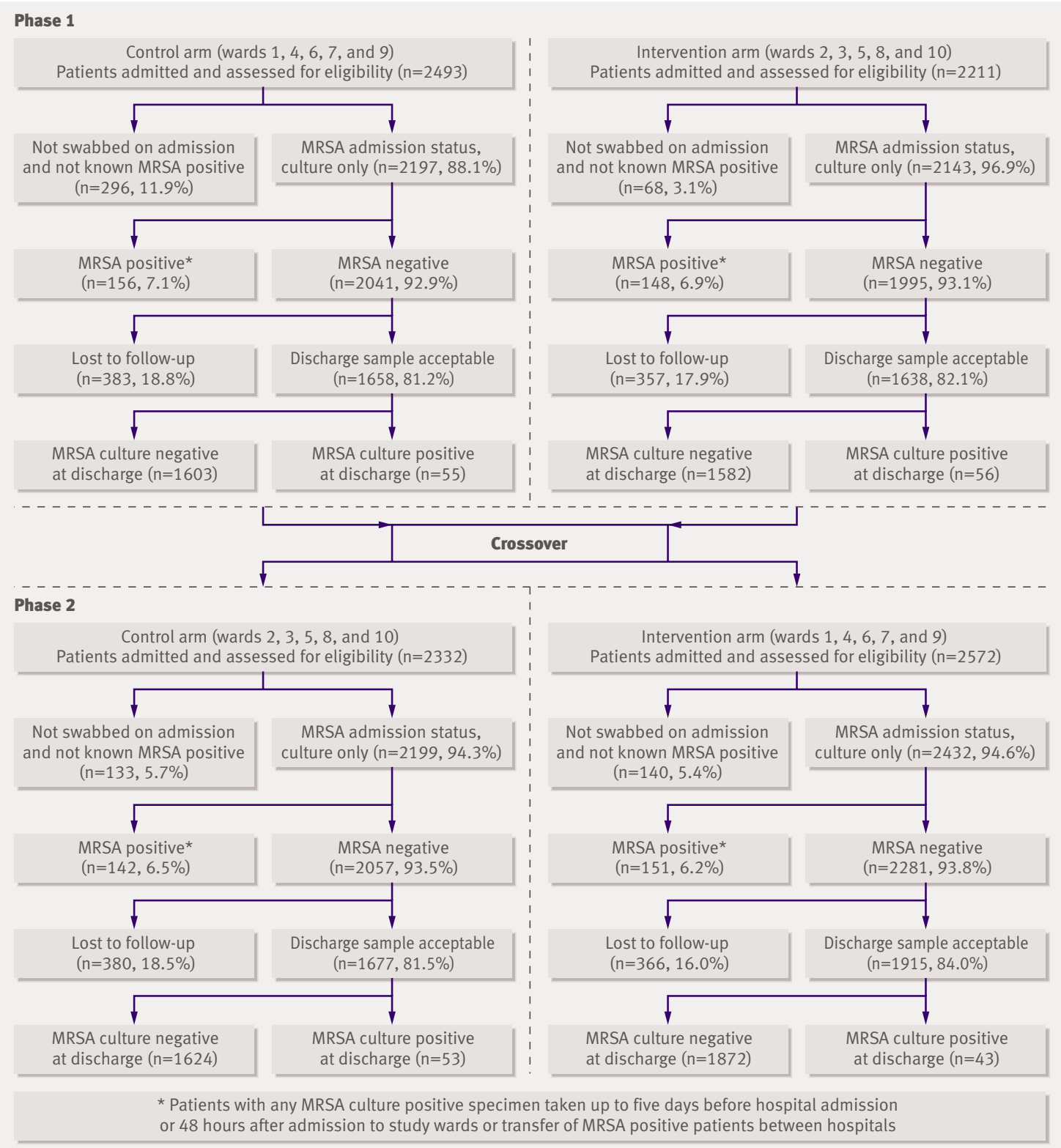

\section{Flow of patients through study}

discharge, either because of an oversight by nursing staff or because the patients left the hospital before being swabbed. The remaining patients were swabbed but the samples at discharge were not from the correct anatomical sites. Thus 6888 patients had full data and were eligible, $3335(81.4 \%)$ in the control arm and 3553 $(83.1 \%)$ in the rapid test arm. The intervention was carried out in $4528(99.0 \%)$ patients. Table 1 shows the baseline characteristics of the patients in both study arms and table 2 the characteristics of the wards.

MRSA was acquired by $108(3.2 \%)$ patients in the control arm and $99(2.8 \%)$ in the intervention arm. The control and intervention arms did not differ for MRSA acquisition rate (unadjusted odds ratio $0.88,95 \%$ confidence interval 0.52 to $1.46, \mathrm{P}=0.61$ ), MRSA acquisition rate per 1000 patient days at risk (4.9 in the control arm, 4.4 in the rapid test arm; incidence rate ratio $0.90,95 \%$ confidence interval 0.69 to $1.2, \mathrm{P}=0.27$ ) and transmission rate $(0.36$ in the control arm, 0.33 in the rapid test arm, incidence rate ratio $0.85,0.64$ to $1.12, \mathrm{P}=0.24)$. This was unchanged when the acquisition rate was adjusted using generalised estimating equation regression for the predefined confounders (adjusted odds ratio $0.91,95 \%$ confidence interval 0.61 to $1.34, \mathrm{P}=0.63$ ). At the rate of acquisition seen in the control arm, the study had the power to detect a reduction to $2 \%$.

In the restricted analysis 17 patients in the control arm and 15 in the rapid test arm were excluded because they had a study ward stay of 48 hours or less $(n=15)$ or they had been MRSA culture positive in the three months before admission $(\mathrm{n}=16)$; one patient had both With these exclusions the adjusted odds ratio in 


\begin{tabular}{|c|c|c|c|c|c|c|c|c|}
\hline \multirow[b]{2}{*}{ Ward No } & \multicolumn{2}{|c|}{ Importation pressure* } & \multirow[b]{2}{*}{$\begin{array}{l}\text { Odds ratio }(95 \% \mathrm{Cl}) \text { for } \\
\text { MRSA acquisition rate }\end{array}$} & \multirow[b]{2}{*}{$P$ value } & \multicolumn{2}{|c|}{$\begin{array}{l}\text { MRSA transmission } \\
\text { rate }\end{array}$} & \multicolumn{2}{|c|}{$\begin{array}{c}\text { MRSA acquisition per } \\
1000 \text { patient days }\end{array}$} \\
\hline & $\begin{array}{l}\text { Control } \\
\text { group (\%) }\end{array}$ & $\begin{array}{l}\text { Rapid test } \\
\text { group (\%) }\end{array}$ & & & $\begin{array}{l}\text { Control } \\
\text { group }\end{array}$ & $\begin{array}{l}\text { Rapid test } \\
\text { group }\end{array}$ & $\begin{array}{l}\text { Control } \\
\text { group }\end{array}$ & $\begin{array}{l}\text { Rapid test } \\
\text { group }\end{array}$ \\
\hline 1 & 6.8 & 3.7 & 0.59 (0.13 to 2.64$)$ & 0.49 & 0.12 & 0.14 & 1.88 & 1.33 \\
\hline 2 & 15.5 & 19.0 & $2.61(0.24$ to 5.52$) \dagger$ & 0.01 & 0.36 & $0.58 \dagger$ & 4.69 & $9.43 \dagger$ \\
\hline 3 & 7.0 & 6.1 & $1.20(0.57$ to 2.54$)$ & 0.63 & 0.25 & 0.35 & 5.89 & 7.61 \\
\hline 4 & 4.8 & 5.1 & $1.00(0.47$ to 2.1$)$ & 0.99 & 0.33 & 0.32 & 5.17 & 5.29 \\
\hline 5 & 3.6 & 2.7 & $0.50(0.15$ to 1.67$)$ & 0.26 & 0.42 & 0.29 & 3.71 & 1.87 \\
\hline 6 & 19.7 & 14.8 & 0.31 (0.15 to 0.67$) \dagger$ & $<0.01$ & $0.65 \dagger$ & 0.34 & $10.25 \dagger$ & 5.92 \\
\hline 7 & 7.9 & 8.4 & 1.14 (0.47 to 2.77$)$ & 0.78 & 0.27 & 0.28 & 3.94 & 4.66 \\
\hline 8 & 5.1 & 6.8 & 0.51 (0.21 to 1.27$)$ & 0.15 & 0.68 & 0.25 & 6.26 & 2.84 \\
\hline 9 & 5.0 & 4.3 & 0.39 (0.10 to 1.56$)$ & 0.18 & 0.50 & 0.25 & 2.96 & 1.28 \\
\hline $10 / 11$ & 6.0 & 9.2 & $1.60(0.50$ to 5.07$)$ & 0.43 & 0.30 & 0.32 & 3.99 & 4.02 \\
\hline
\end{tabular}

*Proportion of patients positive for MRSA on admission. †Outbreak of MRSA.

generalised estimating equation regression was 0.86 (95\% confidence interval 0.60 to $1.26, \mathrm{P}=0.46$ ).

MRSA wound infections occurred in 22 patients in the control arm and 21 patients in the rapid test arm (odds ratio $0.91,0.48$ to $1.7, \mathrm{P}=0.77$ ). Two MRSA bacteraemias occurred during the control phase and one during the intervention phase $(0.49,0.01$ to 9.1$)$.

\begin{tabular}{|c|c|c|c|c|}
\hline Ward No, specialty & Hospital site & $\begin{array}{l}\text { No of bays and } \\
\text { bed capacity }\end{array}$ & $\begin{array}{l}\text { No of side } \\
\text { rooms }\end{array}$ & No of beds \\
\hline 1 , surgery (plastics) & St Thomas' & $\begin{array}{l}2 \text { bays with } 6 \\
\text { beds, } 3 \text { bays with } \\
4 \text { beds }\end{array}$ & 4 & 28 \\
\hline 2 , elderly care & St Thomas' & $\begin{array}{l}2 \text { bays with } 6 \\
\text { beds, } 3 \text { bays with } \\
4 \text { beds }\end{array}$ & 4 & 28 \\
\hline 3 , surgery (urology) & Guy's & $\begin{array}{l}3 \text { bays with } 6 \\
\text { beds, } 1 \text { bay with } \\
5 \text { beds }\end{array}$ & 3 & 26 \\
\hline 4 , surgery (ear, nose, and throat) & Guy's & $\begin{array}{l}4 \text { bays with } 6 \\
\text { beds, } 1 \text { bay with } \\
4 \text { beds }\end{array}$ & $\begin{array}{c}6 \text { (5 rooms with } 1 \\
\text { bed, } 1 \text { room with } \\
2 \text { beds) }\end{array}$ & 35 \\
\hline 5 , surgery (cardiothoracic) & Guy's & $\begin{array}{l}1 \text { bay with } 15 \\
\text { beds, } 1 \text { bay with } \\
14 \text { beds }\end{array}$ & 3 & 32 \\
\hline 6 , elderly care & St Thomas' & $\begin{array}{l}2 \text { bays with } 6 \\
\text { beds, } 3 \text { bays with } \\
4 \text { beds }\end{array}$ & 4 & 28 \\
\hline 7 , surgery (vascular) & St Thomas' & $\begin{array}{l}2 \text { bays with } 6 \\
\text { beds, } 3 \text { bays with } \\
4 \text { beds }\end{array}$ & 4 & 28 \\
\hline 8, surgery (gastrointestinal) & St Thomas' & $\begin{array}{l}2 \text { bays with } 6 \\
\text { beds, } 3 \text { bays with } \\
4 \text { beds }\end{array}$ & 4 & 28 \\
\hline 9, oncology & Guy's & $\begin{array}{l}1 \text { bay with } 9 \\
\text { beds, } 1 \text { bay with } \\
4 \text { beds }\end{array}$ & 12 & 25 \\
\hline 10 , oncology & Guy's & $\begin{array}{l}2 \text { bays with } 12 \\
\text { beds }\end{array}$ & 4 & 28 \\
\hline 11 , oncology & Guy's & $\begin{array}{l}2 \text { bays with } 10 \\
\text { beds }\end{array}$ & 4 & 24 \\
\hline
\end{tabular}

Wards $2,3,5,8$, and 10 were randomised to receive the intervention first.
MRSA was endemic on the study wards (table 3). Ward results varied but no systematic significant difference was found in MRSA acquisition or transmission rates between the intervention and control arms on individual wards, except during an MRSA outbreak that occurred on one ward during the control phase and another ward during the intervention phase.

A univariable analysis (table 4) showed that MRSA acquisition was associated with compliance with hand hygiene policy, the number of days that MRSA culture positive patients were cohort nursed on the open ward, and the number of days that MRSA culture positive patients were on the open ward but were not cohort nursed. When these potential independent factors were included in the generalised estimating equation regression model the adjusted odds ratio for MRSA acquisition was 0.85 (95\% confidence interval 0.65 to 1.13 , $\mathrm{P}=0.26)$.

The control and intervention arms differed significantly in number of inappropriately isolated or cohorted days (399 $v 277$, respectively, $\mathrm{P}<0.001$ ). In the control arm 303 days inappropriately isolated or cohorted $(75.9 \%)$ and in the intervention arm 221 such days $(79.8 \%)$ were spent in side rooms. The proportion of patients who were pre-emptively isolated or cohort nursed was similar between the two arms $(5 \%$ in the control arm, $4.7 \%$ in the rapid test arm). A small, statistically insignificant difference was found for the number of inappropriate open days between the two arms (389 in the control arm $v 351$ in the rapid test arm, $\mathrm{P}=0.08$ ). Using culture only (comparing like with like) the difference in the number of inappropriate open days between the two arms was statistically significant (389 in the control arm $v 213$ in the rapid test arm, $\mathrm{P}<0.001)$.

Four of $4558(0.09 \%)$ tests on admission samples did not produce a result owing to inhibition of the polymerase chain reaction. For the remaining specimens the sensitivity of the rapid test compared with conventional culture was $87.8 \%$ and the specificity was 
96.3\% (positive predictive value 55.1\%, negative predictive value $99.4 \%$; table 5 ).

The median (interquartile range) turnaround time from admission, including portering, processing, and reporting, was 46.4 hours (39.1-66.1) for conventional culture in the control phase and 21.8 hours (17.9-25.4) for the rapid test $(\mathrm{P}<0.001)$. The time between a positive result being available electronically and being telephoned to the ward during the rapid phase was calculated for $260 \mathrm{MRSA}$ positive patients; four $(1.5 \%)$ were telephoned the day before the computer result, $217(83 \%)$ the same day, $31(11 \%)$ the day after, six $(2.3 \%)$ two days after, and one $(0.38 \%)$ each three and four days after.

Seven of the included patients who were MRSA culture negative on admission and MRSA culture positive by discharge were positive on admission using the polymerase chain reaction test; these cases were counted as MRSA acquisitions by study definitions. When these patients were excluded from the analysis the difference in MRSA acquisition between the two arms remained statistically insignificant $(\mathrm{P}=0.13)$.

An outbreak of MRSA occurred in one ward during the intervention phase (closed for six days) and another ward during the control phase (closed for five days). Because of diarrhoea and vomiting outbreaks, one study ward closed for eight days (intervention phase), another for 11 days (control phase), and another for one day (intervention phase). One ward closed permanently in November 2006 (control phase) and a similar ward was recruited. Since this could have affected results a restricted analysis was undertaken with the

\begin{tabular}{|c|c|c|c|}
\hline Variables & $\begin{array}{l}\text { Median (interquartile } \\
\text { range) per month }\end{array}$ & $\begin{array}{l}\text { Univariable analysis odds } \\
\text { ratio }(95 \% \mathrm{Cl})\end{array}$ & $P$ value \\
\hline$\beta$ lactam antibiotics* & $659.75(316.57-1354.03)$ & 0.807 (0.614 to 1.060$)$ & 0.123 \\
\hline Ciprofloxacin* & $214.30(127.50-542.50)$ & 1.000 (0.392 to 2.532$)$ & 0.993 \\
\hline Anti-MRSA antibiotics* & $15.01(7.93-26.71)$ & 0.594 (0.010 to 35.079) & 0.802 \\
\hline Occupied bed days & $654(568-746)$ & $4.66(0.20$ to 111.19$)$ & 0.342 \\
\hline $\begin{array}{l}\text { Importation pressure† (per } \\
1000 \text { admissions) }\end{array}$ & $53(36.75-95.75)$ & $1.002(0.998$ to 1.006$)$ & 0.326 \\
\hline Hand washing compliance (\%) & $41.7(20.0-51.58)$ & $1.080(1.028$ to 1.134$)$ & $0.002 \ddagger$ \\
\hline Patient days§ & $2(0-10.00)$ & $1.113(0.979$ to 1.265$)$ & $0.101 \ddagger$ \\
\hline Patient days & $0(0-1)$ & 1.055 (1.020 to 1.091$)$ & $0.002 \ddagger$ \\
\hline $\begin{array}{l}\text { MRSA positive on admission } \\
\text { but isolated (any reason) } \\
\text { before positive result (\%) }\end{array}$ & $33(16.5-50)$ & 0.995 (0.986 to 1.004$)$ & 0.264 \\
\hline Staff turnover & $0(0-2.44)$ & 1.041 (0.986 to 1.099$)$ & 0.144 \\
\hline $\begin{array}{l}\text { Staffing levels (whole time } \\
\text { equivalents/open bed) }\end{array}$ & $0.79(0.67-0.93)$ & 0.235 (0.438 to 1.263$)$ & 0.092 \\
\hline $\begin{array}{l}\text { No of ward beds open (not } \\
\text { side room) }\end{array}$ & $28(26-28)$ & $0.974(0.879$ to 1.079$)$ & 0.612 \\
\hline No of side rooms open & $4(4-4)$ & 1.301 (0.783 to 2.163$)$ & 0.310 \\
\hline $\begin{array}{l}\text { Use of bank and agency staff } \\
\text { (whole time equivalents) }\end{array}$ & $2.9(1.69-5.37)$ & 0.945 (0.840 to 1.062$)$ & 0.341 \\
\hline \multicolumn{4}{|c|}{$\begin{array}{l}\text { MRSA=meticillin resistant Staphylococcus aureus. } \\
\text { *Defined daily doses, according to World Health Organization standardised measure of drug consumption. } \\
\text { †Proportion of patients MRSA positive on admission. } \\
\text { flncluded in multivariable analysis. } \\
\text { §MRSA culture positive patients cohort nursed on open ward. } \\
\text { TMRSA culture positive patients on open ward but not cohort nursed. }\end{array}$} \\
\hline
\end{tabular}

closed ward and recruited ward removed; this made little difference to the MRSA acquisition rate (adjusted odds ratio $0.90,95 \%$ confidence interval 0.65 to 1.24 , $\mathrm{P}=0.52)$. One of the study wards moved to the location of the closed ward in February 2007 (control phase). A further ward had some refurbishment and cleaning over nine days (intervention phase).

\section{DISCUSSION}

Reducing cross infection with meticillin resistant Staphylococcus aureus (MRSA) is a major priority of the National Health Service and early detection of MRSA seems a logical addition to current control measures. This randomised trial found that under operational conditions rapid testing for MRSA reduced the time taken for wards to get results and had an impact on patient isolation and cohort nursing. We found no evidence of a significant reduction of MRSA acquisition $(3.2 \% \vee 2.8 \%, \mathrm{P}=0.61)$. This magnitude of reduction (four per 1000 patients) is unlikely to be large enough, even if it were statistically significant, to influence policy on MRSA control given the cost implications and the evidence of effective, cheaper, alternative strategies. A trial of more than 60000 patients would be required to detect the size of difference found here. MRSA transmission and infection rates were also not significantly different between the intervention and control arms.

Potential confounding factors, including antibiotic use, importation pressure (proportion of patients positive for MRSA on admission), and compliance with hand hygiene did not explain the lack of a difference. In this hospital, patients positive for MRSA are either isolated or cohort nursed on the open ward and given decontamination treatment, following national guidelines. We found no evidence that deploying universal rapid testing would improve usefully on universal culture testing to reduce rates of MRSA. The trial cannot exclude a small difference, or address the real possibility that rapid testing in high risk environments such as intensive care units is effective.

Our results are contrary to theoretical expectations and differ from a non-controlled study in an intensive care unit. $^{13}$ Another uncontrolled study in intensive care units showed a reduction in MRSA infections when pre-emptive isolation was added to rapid testing; the key intervention may be pre-emptive isolation. ${ }^{14} \mathrm{~A}$ third non-randomised study reduced the potential advantage of the test by prolonging the turnaround time and found a statistically insignificant difference in MRSA rates. ${ }^{15}$ Another uncontrolled study associated a reduction of MRSA bacteraemia and wound infection rates with the introduction of rapid tests. The limitations of this study are acknowledged by the authors who state that causality could not be confirmed. ${ }^{16}$ A prospective study in surgical patients found that universal, rapid MRSA screening in addition to standard infection control measures did not reduce nosocomial MRSA infection rates when compared with standard infection control measures alone. $^{17}$ 
Table 5 Characteristics of rapid polymerase chain reaction test for meticillin resistant Staphylococcus aureus (MRSA) in samples taken on admission

\begin{tabular}{lccc} 
& \multicolumn{2}{c}{ MRSA culture result } & \\
\cline { 2 - 3 } Variable & Positive & Negative & No of admission samples \\
Rapid test result: & & 159 & 354 \\
\hline Positive & $195(87.8)^{\star}$ & $4173(96.3)^{\star}$ & 4200 \\
\hline Negative & 27 & 4332 & 4554 \\
\hline No of admission samples & 222 & & \\
\hline
\end{tabular}

*Number (percentage) of samples.

We found no evidence that our study hospitals responded less well to a positive MRSA result than other hospitals in the UK. Most patients with MRSA were isolated in side rooms and we found no evidence of an increased risk of MRSA acquisition when MRSA positive patients were nursed on the open ward (data not shown). Importation pressure was similar to another, local hospital ${ }^{23}$ and to the centres that reported a reduction of MRSA rates with rapid MRSA screening. ${ }^{131416}$ Rates for hand hygiene were similar to or better than those found at other UK hospitals. ${ }^{2425}$ Robust data on MRSA acquisition and transmission rates are lacking ${ }^{626}$ and as these measurements depend on ward case mix, comparison is difficult. Our rates are in keeping with good, non-outbreak studies that include general wards ${ }^{6-28}$ and do not suggest unusually poor MRSA control. The wards were chosen as representative of the settings where MRSA transmission occurs in the UK. The outbreaks and ward closures that occurred during this study are not untypical for hospital practice. Although no two settings are identical, there is no obvious reason to believe that our findings cannot be generalised to other settings.

In principle, rapid detection of MRSA will have the greatest effect when control measures are relatively weak for patients with undiagnosed MRSA carriage on admission. In the present study $30 \%$ of patients subsequently found to be MRSA culture positive on admission were pre-emptively isolated before test results were available, but this is not universal practice elsewhere. The potential importance of pre-emptive isolation for MRSA control has already been highlighted. ${ }^{14}$ Additionally, our policy is to nurse patients with standard precautions for their entire

\section{WHAT IS ALREADY KNOWN ON THIS TOPIC}

Universal screening for MRSA has been suggested by the UK Department of Health

Rapid tests are under consideration but the expense of these test means they require proper investigation: currently available data cannot be extrapolated to general wards

\section{WHAT THIS STUDY ADDS}

Compared with conventional methods, universal rapid screening for MRSA on admission did not reduce MRSA rates on general wards where pre-emptive isolation was in place, to a level of public health significance, given the cost implications

Although an impact was found on isolation and barrier nursing, formal cost effectiveness analysis is needed

Universal rapid screening for MRSA across the NHS is not recommended on the data presented hospital stay, regardless of their risk factors for MRSA. It is therefore possible that a more positive result would be seen for rapid testing in settings where these practices are used only for those identified as having MRSA.

We specifically set out to assess a rapid test for MRSA in a typical NHS setting; we did not alter infection control practices, staffing, transport of specimens, or communication of MRSA results to the wards. Such changes might have enhanced the potential benefits of the rapid test but would have demanded greater resources and costs and would be unlikely to be generalisable. The rapidity of the test was, however, not compromised. ${ }^{1314}$

The rapid test performed well. In common with most operational studies of diagnostic tests its sensitivity was lower in routine practice than initial validation studies, but our results are similar to those reported by others. ${ }^{2930}$ Evidence is lacking that other rapid tests perform better. The test is validated for use on nasal swabs only and we optimised it for multiple site specimens because the use of nasal swabs alone detects only $78.5 \%$ of patients found to be MRSA positive after screening of multiple sites. ${ }^{31}$

Efficient use of limited isolation resources is important for the control of both MRSA and other nosocomial infections. Rapid tests could be beneficial or cost beneficial if they allowed isolation resources to be freed up more quickly. In this study there were fewer inappropriately isolated or cohorted days with rapid testing, most of which were in side rooms. This was, however, countered by isolation or cohort nursing of patients detected as positive only by the rapid test. This is a potential further cost of polymerase chain reaction based tests in addition to the substantially higher consumable costs. ${ }^{15}$ Formal cost benefit analysis is needed.

The control of MRSA is an NHS and political priority, and technological solutions have clear appeal. In this study on general wards a rapid MRSA screening result did not, by itself, reduce MRSA rates to a degree likely to justify the cost. This hospital has MRSA pressure and infection control practices similar to or more intensive than comparable NHS institutions. Rapid testing may have a role in outbreak control, emergency surgical screening, or high risk patients such as those on intensive care units. In general medical and surgical settings prioritising rapid testing over optimising other control measures such as universal MRSA screening, pre-emptive isolation of patients at high risk of MRSA, and good infection control practice is not supported by this study.

We thank the patients and staff on the following wards-Alan Apley, Alexandra, Aston Key, Blundell, Dorcas, Henry, Hedley Atkins, Luke, Page, Samaritan, and Stanley, and the surgical admissions lounge; the Department of Infection; Ghasem Yadeghafar, Florence Bunting, Sarah Sacks, Edel Dunkerley, and other staff of Electronic Patient Records; the staff of performance management; and the staff of the information team in the human resources department.

Contributors: GLF initiated the project. DJ, CJMW, and GLF designed the study. DJ set up and ran the study and is the guarantor. DJ, KM, and UA collected and cleaned the data. CO, DJ, and CJMW created the database 
and CO helped with data extraction. DJ, DL, and CJMW did the statistical analysis. DJ, CJMW, and GLF drafted the paper, to which all authors contributed.

Funding: This study was funded by the UK Department of Health and sponsored by Guy's and St Thomas' NHS Foundation Trust. The funding source did not have any role in the study design, execution, analysis, writing of the manuscript or conclusions.

Competing interests: None declared.

Ethical approval: Ethical approval was given by the Guy's and St Thomas' central office for research ethics committees.

1 Health Protection Agency. Commentary on quarterly, six monthly and annual data for MRSA bacteraemia derived from mandatory surveillance. London: HPA, July

2007. www.hpa.org.uk/publications/2007/HCAl/hcai.pdf.

2 Cosgrove SE, Sakoulas G, Perencevich EN, Schwaber MJ, Karchmer AW, Carmeli Y. Comparison of mortality associated with methicillin-resistant and methicillin-susceptible Staphylococcus aureus bacteremia: a meta-analysis. Clin Infect Dis 2003;1;36:53-9.

3 Engemann JJ, Carmeli Y, Cosgrove SE, Fowler VG, Bronstein MZ, Trivette SL, et al. Adverse clinical and economic outcomes attributable to methicillin resistance among patients with Staphylococcus aureus surgical site infection. Clin Infect Dis 2003;36:592-8.

4 Chief Medical Officer. Winning ways: working together to reduce healthcare associated infection in England. Report from the Chief Medical Officer. London: Department of Health, December 2003.

5 Robotham JV, Scarff CA, Jenkins DR, Medley GF. Meticillin-resistant Staphylococcus aureus (MRSA) in hospitals and the community: model predictions based on the UK situation. J Hosp Infect 2007;65(suppl 2):93-9.

6 Ritchie K, Bradbury I, Eastgate J, Foster L, Iqbal, K, MacPherson K, et al. Consultation report on health technology. Clinical and cost effectiveness of screening for MRSA. NHS Quality Improvement Scotland, 2006.

7 Rubinovitch B, Pittet D. Screening for methicillin-resistant Staphylococcus aureus in the endemic hospital: what have we learned? J Hosp Infect 2001;47:9-18.

8 Coia JE, Duckworth GJ, Edwards DI, Farrington M, Fry C, Humphreys H, et al. Joint Working Party of the British Society of Antimicrobial Chemotherapy; Hospital Infection Society; Infection Control Nurses Association. Guidelines for the control and prevention of meticillinresistant Staphylococcus aureus (MRSA) in healthcare facilities. I Hosp Infect 2006;63(suppl 1):S1-44.

9 Duckworth G, Cookson B, Humphreys H, Heathcock R. Revised methicillin-resistant Staphylococcus aureus infection control guidelines for hospitals. Report of a Working Party of the British Society for Antimicrobial Chemotherapy, the Hospital Infection Society and the Infection Control Nurses Association. J Hosp Infect 1998;39:253-90.

10 Mulligan ME, Murray-Leisure KA, Ribner BS, Standiford HC, John JF, Korvick JA, et al. Methicillin-resistant Staphylococcus aureus: a consensus review of the microbiology, pathogenesis, and epidemiology with implications for prevention and management. $A m$ Med 1993;94:313-28.

11 Muto CA, Jernigan JA, Ostrowsky BE, Richet HM, Jarvis WR, Boyce JM, et al. SHEA guidelines for preventing nosocomial transmission of multi-drug resistant strains of Staphylococcus aureus and Enterococcus. Infect Control Hosp Epidemiol 2003;24:362-86.

12 Department of Health. Screening for meticillin-resistant Staphylococcus aureus (MRSA) colonisation. A strategy for NHS trusts a summary of best practice. London: DoH, 2007.

13 Cunningham R, Jenks P, Northwood J, Wallis M, Ferguson S, Hunt S. Effect on MRSA transmission of rapid PCR testing of patients admitted to critical care. J Hosp Infect 2007;65:24-8.

14 Harbarth S, Masuet-Aumatell C, Schrenzel J, Francois P, Akakpo C, Renzi G, et al. Evaluation of rapid screening and pre-emptive contact isolation for detecting and controlling methicillin-resistant Staphylococcus aureus in critical care: an interventional cohort study. Crit Care Med 2006;10:R25.
15 Conterno LO, Shymanski J, Ramotar K, Toye B, van Walraven C, Coyle $\mathrm{D}$, et al. Real-time polymerase chain reaction detection of methicillin-resistant Staphylococcus aureus: impact on nosocomial transmission and costs. Infect Control Hosp Epidemiol 2007;28:1134-41.

16 Keshtgar MR, Khalili A, Coen PG, Carder C, Macrae B, Jeanes A, et al. Impact of rapid molecular screening for meticillin-resistant Staphylococcus aureus in surgical wards. Br J Surg 2008;95:381-6.

17 Harbarth S, Fankhauser C, Schrenzel J, Christenson J, Gervaz P, Bandiera-Clerc C, et al. Universal screening for methicillin-resistant Staphylococcus aureus at hospital admission and nosocomial infection in surgical patients. JAMA. 2008;299:1149-57.

18 Pratt RJ, Pellowe CM, Wilson JA, Loveday HP, Harper PJ, Jones SR, et al. epic2: National evidence-based guidelines for preventing healthcareassociated infections in NHS hospitals in England. J Hosp Infect 2007;65(suppl 1):S1-64.

19 Gurran C, Holliday MG, Perry JD, Ford M, Morgan S, Orr KE. A nove selective medium for the detection of methicillin-resistant Staphylococcus aureus enabling result reporting in under $24 \mathrm{~h}$. J Hosp Infect 2002;52:148-51.

20 Brown DFJ, Edwards DI, Hawkey PM, Morrison D, Ridgway GL, Towner KJ, et al. On behalf of the joint working party of the British Society for Antimicrobial Chemotherapy, Hospital Infection Society and Infection Control Nurses Association. Guidelines for the laboratory diagnosis and susceptibility testing of methicillin-resistant Staphylococcus aureus (MRSA). J Antimicrob Chemother 2005;56:1000-101.

21 Jeyaratnam D, Gottlieb A, Ajoku U, French GL. Validation of the IDIMRSA $^{\mathrm{TM}}$ system for use on pooled nose, axilla and groin swabs, and single swabs from other screening sites. Diagn Microbiol Infect Dis 2008 Jan 15. [Epublication ahead of print.]

22 American Society of Anesthesiologists. New classification of physical status. Anesthesiology 1963;24:111.

23 G Gopal Rao, Michalczyk P, Nayeem N, Walker G, Wigmore L. Prevalence and risk factors for meticillin-resistant Staphylococcus aureus in adult emergency admissions: a case for screening all patients? J Hosp Infect 2007;66:15-21.

24 Cepeda J, Whitehouse T, Cooper B, Hails J, Jones K, Kwaku F, et al. Isolation of patients in single rooms or cohorts to reduce spread of MRSA in intensive-care units: prospective two-centre study. Lancet 2005;365:295-304.

25 MacDonald A, Dinah F, MacKenzie D, Wilson A. Performance feedback of hand hygiene, using alcohol gel as the skin decontaminant, reduces the number of inpatients newly affected by MRSA and antibiotic costs. J Hosp Infect 2004;56:56-63.

26 Cooper BS, Medley GF, Stone SP, Kibbler CC, Cookson BD, Roberts JA, et al. Methicillin-resistant Staphylococcus aureus in hospitals and the community: stealth dynamics and control catastrophes. Proc Natl Acad Sci 2004;101:10223-8.

27 Farrington M, Redpath C, Trundle C, Coomber S, Brown NM. Winning the battle but losing the war: methicillin-resistant Staphylococcus aureus (MRSA) infection at a teaching hospital. $Q J$ Med 1998;91:539-48.

28 Rioux C, Armand-Lefevre L, Guerinot W, Andremont A, Lucet J-C. Acquisition of methicillin-resistant Staphylococcus aureus in the acute care setting: incidence and risk factors. Infect Control Hosp Epidemiol 2007;28:733-6.

29 Bishop E, Grabsch EA, Ballard SA, Mayall B, Xie S, Martin R, et al. Concurrent analysis of nose and groin swab specimens by the IDIMRSA PCR assay is comparable to analysis by individual specimen PCR and routine culture assays for detection of colonization by methicillin-resistant Staphylococcus aureus. J Clin Microbiol 2006;44:2904-8.

30 Warren DK, Liao RS, Merz LR, Eveland M, Dunne WM. Detection of methicillin-resistant Staphylococcus aureus directly from nasal swab specimens by a real-time PCR assay. J Clin Microbiol 2004; $42: 5578-81$

31 Coello R, Jimenez J, Garcia M, Arroyo P, Minguez D, Fernández C, et al. Prospective study of infection, colonisation and carriage of methicillin-resistant Staphylococcus aureus in an outbreak affecting 990 patients. Eur J Clin Microbiol Infect Dis 1994;13:74-81.

Accepted: 7 March 2008 